\title{
An investigation of plant-induced suction and its implications for slope stability
}

Anil Yildiz Dr Sc.

Postdoctoral Researcher, Institute for Geotechnical Engineering, ETH Zurich, Zurich, Switzerland; Guest Researcher, WSL Institute for Snow and

Avalanche Research SLF, Davos Dorf, Switzerland; Guest Researcher, Swiss Federal Institute for Forest, Snow and Landscape Research WSL, Birmensdorf, Switzerland (corresponding author: anil.yildiz@igt.baug.ethz.ch)

(Orcid:0000-0002-2257-7025)

Frank Graf Dr Sc. Nat.

Scientific Staff Member, WSL Institute for Snow and Avalanche Research

SLF, Davos Dorf, Switzerland
Sarah M. Springman CBE, FREng, MA, MPhil, PhD, DSC (h.c.) mult., DPhil (h.c.), DEng (h.c.), FICE, FWES, MInstRE, SIA Professor, Institute for Geotechnical Engineering, ETH Zurich, Zurich, Switzerland

Both above- and below-ground biomass of plants provide additional strength to soil through different mechanisms, which help to increase the stability of a vegetated slope. Nonetheless, shallow landslides on steep slopes covered with vegetation still occur, often being triggered above the groundwater table, due to loss of suction subsequent to rainfall. Therefore, it is essential to know to what extent vegetation enhances slope stability, and to quantify the contribution of vegetation to the shear strength of soil to determine factors of safety. Results of large-scale direct shear experiments on root-permeated soils and slope geometry from a landslide database were synthesised through an infinite slope analysis under partially saturated conditions to find critical combinations of slope angle and suction stress. Monte Carlo simulations yielded a clear separation of stable and unstable zones, which can be used to define the susceptibility of a slope to near surface failure. This method, based on the simulations, has the potential to be used as a regional early warning system.

\author{
Notation \\ $c^{\prime} \quad$ drained cohesion intercept \\ $L \quad$ length of landslide \\ $N \quad$ number of Monte Carlo simulations \\ $\left(u_{\mathrm{a}}-u_{\mathrm{w}}\right) \quad$ matric suction \\ $z \quad$ depth of landslide \\ $\alpha, n \quad$ parameters of Van Genuchten (1980) equation \\ $\beta \quad$ slope angle \\ $\gamma \quad$ bulk unit weight \\ $\kappa \quad$ scale factor of Weibull distribution \\ $\lambda$ shape factor of Weibull distribution \\ $\mu \quad$ mean value \\ $\sigma^{\mathrm{S}} \quad$ suction stress \\ $\phi^{\prime} \quad$ internal friction angle
}

\section{Introduction}

A slope would be marginally stable when the slope angle is equal to the internal friction angle of dry soil. Any additional shear strength can be mobilised due to suction, vegetation, or any other stabilising agents for a slope with an angle steeper than the internal friction angle of the soil. This additional strength due to suction can be lost either after a heavy rainfall event over a short duration (Brand et al., 1984; D'Amato Avanzi et al., 2004; Guzzetti et al., 2004) or more moderate rainfall over a long duration (Lumb, 1975). This loss, or even a decrease in suction, can trigger rainfall-induced landslides (Greco et al., 2010; Picarelli et al., 2016; Urciuoli et al., 2016).

Conventional civil engineering techniques - for example, soil nailing or shotcrete, were common slope stabilisation measures in the past (Leung et al., 2015), whereas plants have been recognised widely as sustainable and eco-friendly alternatives owing to

- provision of mechanical resistance from root tensile strength (Graf et al., 2009; Gray and Barker, 2004; Wu et al., 1979)

- reduction in water content of soil through canopy interception and root water uptake results in partial saturation of shallow soil layers, causing an increase in matric suction (Simon and Collison, 2002).

Hydrological reinforcement function of plants can even lead to greater increase in strength than their mechanical function (Boldrin et al., 2018; Pollen-Bankhead and Simon, 2010). However, the increase in factor of safety $(\mathrm{FoS})$ of a vegetated slope due to plant-induced suction fluctuates throughout a year due to the seasonal variation effects of vegetation on the hydrological regime of a slope, which has been shown to be most significant during dry periods (Kim et al., 2017; Leung and $\mathrm{Ng}, 2013$ )

An extreme rainfall event in late August 2005 caused considerable damage, and even loss of lives, by landslides, floods and debris flows in large parts of Switzerland (Hilker et al., 2009). Three landslide inventories were collected after the rainfall in August 2005 from three regions in Switzerland, namely, Entlebuch, Napf and Praettigau, by Rickli and Graf (2009). In their study, 133 shallow landslides were documented from these regions, 50 of which happened on forested slopes. In order to understand better how vegetation influences slope 
stability, it is essential to know how changes in the plantinduced suction affect the shear strength of soil and how these changes are reflected in terms of increased stability.

Rickli and Graf (2009) recorded information on 522 shallow landslides, of which 240 took place on forested slopes, from six different locations in Switzerland. Table 1 shows the number of landslides and the slope angles for each study site. The increase in the stability of the slope due to vegetation can be seen virtually in the differences between angles of the slopes on which the landslides took place, in the forest area and open land. Higher angles were observed for landslides on the forested slopes for all locations. The effects of vegetation on the slope stability, either due to mechanical root reinforcement or plantinduced suction, have been demonstrated in the past with varying methods, such as infinite slope stability analysis (Chirico et al., 2013), the finite-element method (Mao et al., 2014), probabilistic analyses (Hazra et al., 2017), fibre bundle models (Schwarz et al., 2013) or physical modelling (Leung et al., 2017; Liang and Knappett, 2015). Measured or simulated plant-induced suctions were used in models of slope stability to evaluate the increase in the stability due to vegetation (Rahardjo et al., 2014).

The results of the direct shear experiments presented in Yildiz et al. (2019) and the information on 50 documented landslides from the Praettigau region from a landslide database (Rickli and Graf, 2009) were analysed to reveal how they can be upscaled to improve the understanding of slope stability, since the soil used in the experiments was obtained from one of the locations presented in the landslide database. Combining largescale direct shear tests on planted specimens, measurement of plant-induced suction in the laboratory, and historical landslide data has decreased the number of assumptions. Therefore, it provided a chance to develop a simple tool based on realistic data from different scales. A physically based landslide susceptibility model was developed, referring to the outcomes of Monte Carlo simulations, which were then used to provide insight on which combinations of slope angle and suction stress could trigger a shallow landslide in the Praettigau region.

Table 1. Information about the shallow landslides presented in Rickli and Graf (2009)

\begin{tabular}{lllll} 
& & \multicolumn{3}{c}{ Slope angles: degrees } \\
\cline { 3 - 5 } $\begin{array}{l}\text { Study } \\
\text { area }\end{array}$ & $\begin{array}{l}\text { No. of } \\
\text { landslides }\end{array}$ & Minimum & >90\% & Median \\
\hline Entlebuch & F: 10 O: 37 & F: 26 O: 19 & F: 27 O: 25 & F: 36 O: 29 \\
Praettigau & F: 26 O: 24 & F: 25 O: 23 & F: 28 O: 25 & F: 33 O: 30 \\
Napf '05 & F: 14 O: 22 & F: 25 O: 21 & F: 26 O: 23 & F: 39 O: 27 \\
Napf '02 & F: 30 O: 21 & F: 28 O: 27 & F: 35 O: 30 & F: 39 O: 35 \\
Appenzell & F: 34 O: 48 & F: 26 O: 23 & F: 30 O: 26 & F: 35 O: 31 \\
Sachseln & F: 126 O: 130 & F: 30 O: 28 & F: 35 O: 32 & F: 39 O: 36 \\
\hline
\end{tabular}

$\mathrm{F}$ stands for landslides on the forested slopes, while $\mathrm{O}$ represents landslides on open land

\section{Materials and methods}

\subsection{Study site and soil}

The St Antoenien study site is located near Praettigau in the canton of Grison, Switzerland. Figures 1(a), 1(b) and 1(c) show a photograph of the landslide under investigation, the location of the study site and information on the documented shallow landslides around the study site, respectively. The area has been affected by many landslides during the Holocene epoch, dating back as far as 10000 calendar years before the present, owing to climatic changes, vegetation changes and anthropogenic influences (Dapples et al., 2003).

During the 2005 heavy rainfall event, 26 shallow landslides out of 50 were triggered on forested slopes after a total rainfall of $145 \mathrm{~mm}$ within three consecutive days. The underlying bedrock is Praettigau-Flysch that contributes clayey, sandy debris to mantle the steep slopes, with median slope angles of $33^{\circ}$ and $30^{\circ}$ for forested and open land slopes, respectively (Bezzola and Hegg, 2007; Rickli and Graf, 2009). Soil was obtained from one of the landslide locations, and classified as clayey sand (SC) according to the Unified Soil Classification System (USCS).The index properties of Praettigau soil are given in Table 2.

Yildiz et al. (2019) performed large-scale direct shear tests on planted specimens prepared with Praettigau soil. The biodiversity on a vegetated slope was represented by planting shear boxes with Poa pratensis (L.), Trifolium pratense (L.), Alnus incana (L.) Moench, Achillea millefolium (L.), Anthyllis vulneraria (L.) and Salix appendiculata Vill. Species of genera Salix and Alnus have been used in soil bioengineering applications (Böll et al., 2009), while the other species are found in subalpine grasslands and pastures (Jeangros and Thomet, 2004; Pohl et al., 2009; Stampfli and Zeiter, 2004). Seedlings of the aforementioned species were grown in two different combinations in shear boxes in a climate-controlled chamber for 6 and 12 months. The details of the plant growth and sample preparation can be found in Yildiz et al. (2019).

\subsection{Stability of a partially saturated slope}

Infinite slope analysis is still used as a guide to quantifying slope stability, especially for slopes susceptible to shallow landslides with certain slope length to soil thickness ratios (Wu and Sidle, 1995), although it is rather a simplistic method. Results of finite-element method analyses performed by Griffiths et al. (2011) yielded higher FoS values than infinite slope analysis up to a length to depth ratio $(L / z)$ of 16 . Higher values of $L / z$ resulted in identical $\mathrm{FoS}$ values for both types of analysis. Furthermore, Milledge et al. (2012) showed that FoS values calculated from the finite-element method and infinite slope analysis converge within $5 \%$ when $L / z$ is higher than 25 . Convergence occurred at much lower $L / z$ values, as low as 4 , depending on the material properties of the soil. 


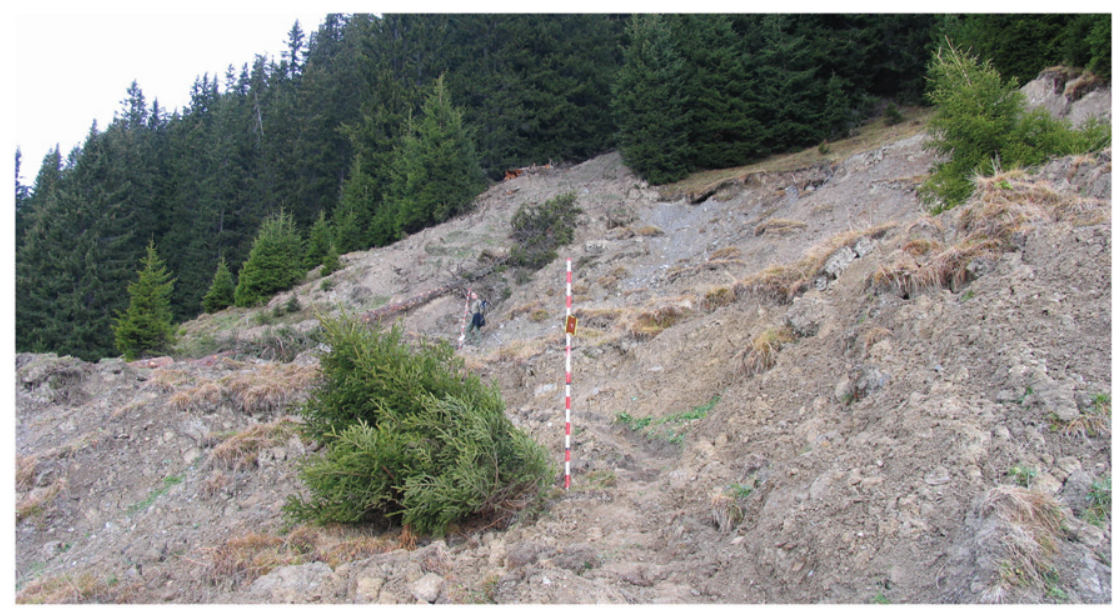

(a)
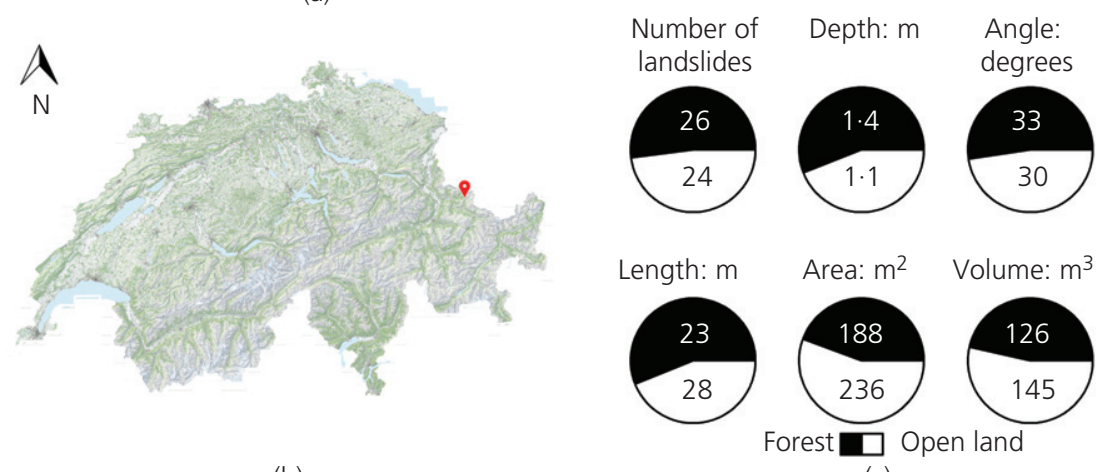

(b)

(c)

Figure 1. (a) Study site in Praettigau after the heavy rainstorm in August 2005 (photograph: Christian Rickli); (b) location of the study site in Switzerland; and (c) information on the landslides in the region (modified from Rickli and Graf (2009)). Landslide statistics are given as the median values

Table 2. Index properties of Praettigau soil

$\begin{array}{lc}\text { Gravel }(>4.75 \mathrm{~mm}): \% & 14 \cdot 1 \\ \text { Sand }(<4.75 \mathrm{~mm} \text { and }>0.074 \mathrm{~mm}): \% & 45 \cdot 6 \\ \text { Fines }(<0.074 \mathrm{~mm}): \% & 40 \cdot 3 \\ \text { Liquid limit: \% } & 23.5 \\ \text { Plastic limit: \% } & 13 \cdot 7 \\ \text { Plasticity index } & 9.8 \\ \text { Specific gravity } & 2.69 \\ \text { USCS classification } & \mathrm{SC}\end{array}$

Figure 2(a) shows the range of $L / z$ values for the landslides in the database for Praettigau. The mean values of $L / z$ were $21 \cdot 2$ and 22.4 for landslides on open land and on forested slopes, respectively, which adds confidence to the predictions. It can be expected that infinite slope analyses can result in a FoS close to that which can be obtained from using the finiteelement method. Askarinejad et al. (2012) investigated twodimensional and three-dimensional slip geometries to quantify the effects of length $(L)$, depth $(z)$ and width $(B)$, confirming that consideration of the side friction results in less conservative values of FoS. Therefore, side friction developing at the edges of the slope was not considered in the analyses.

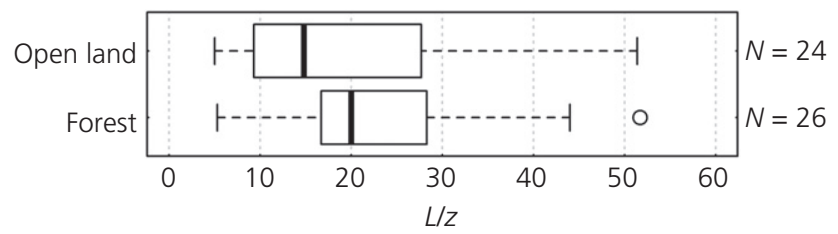

(a)

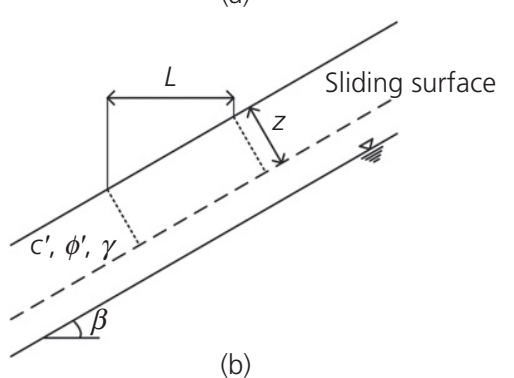

(b)

Figure 2. (a) Boxplot of length to depth ratios (L/Z) of Praettigau landslides on forested $(N=26)$ slopes and open land $(N=24)$. (b) Slope geometry and the parameters used in the infinite slope analyses for partially saturated conditions 
The FoS of a partially saturated slope, as shown in Figure 2(b), can be calculated with Equation 1, where $c^{\prime}$ and $\phi^{\prime}$ are the shear strength parameters of the soil, $\gamma$ is the bulk unit weight, $z$ and $\beta$ are the depth of failure surface and angle of the slope, and $\sigma^{\mathrm{s}}$ is the suction stress, which is dependent on the parameters of the soil-water retention curve (SWRC) $(\alpha, n)$ and matric suction $\left(u_{\mathrm{a}}-u_{\mathrm{w}}\right)$. The equation defined by $\mathrm{Lu}$ and Godt (2008) was modified to define the suction stress as a positive value, for the sake of simplicity for plotting as follows

1. $\mathrm{FoS}=\frac{c^{\prime}}{\gamma z \sin \beta \cos \beta}+\frac{\tan \phi^{\prime}}{\tan \beta}+\sigma^{\mathrm{s}} \frac{\tan \phi^{\prime}}{\gamma z \sin \beta \cos \beta}$

2. $\quad \sigma^{\mathrm{s}}=\frac{\left(u_{\mathrm{a}}-u_{\mathrm{w}}\right)}{\left\{1+\left[\alpha\left(u_{\mathrm{a}}-u_{\mathrm{w}}\right)\right]^{n}\right\}^{(n-1) / n}}$

Table 3. Statistical properties of the parameters used in the sensitivity analysis

\begin{tabular}{|lcccc|} 
& Minimum & Maximum & Mean & Standard deviation \\
\hline$\beta:$ degrees & 23 & 44 & $32 \cdot 3$ & $5 \cdot 24$ \\
$z: \mathrm{m}$ & 0.6 & $2 \cdot 5$ & 1.22 & 0.38 \\
$\gamma: \mathrm{kN} / \mathrm{m}^{3}$ & 18.92 & $20 \cdot 83$ & 19.99 & 0.46 \\
$\sigma^{5}: \mathrm{kPa}$ & $7 \cdot 83$ & 42.5 & $15 \cdot 3$ & 8.08 \\
\hline
\end{tabular}
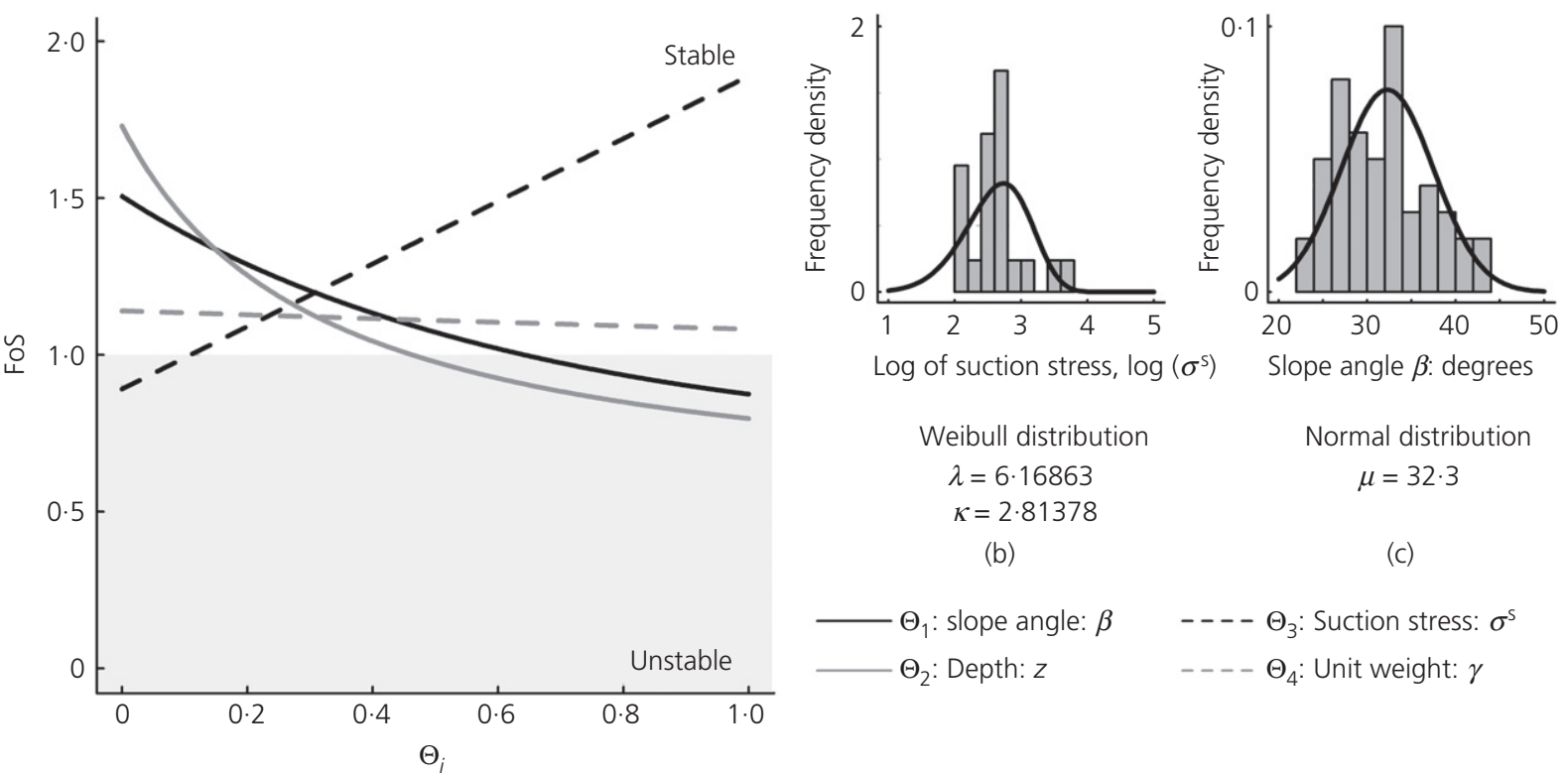

Log of suction stress, $\log \left(\sigma^{s}\right)$

\section{Weibull distribution $\lambda=6 \cdot 16863$ $\kappa=2 \cdot 81378$}

(b)

\section{Normal distribution $\mu=32 \cdot 3$}

(c)

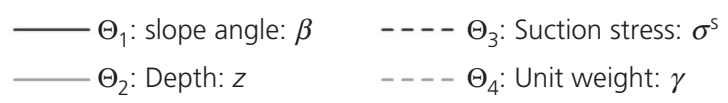




\subsection{Statistical distributions}

The frequency densities of the natural logarithm of the suction stress from the experiments and the slope angle from the landslide database are given in Figures 3(b) and 3(c), respectively. Types of distributions of data were decided using a CullenFrey graph based on the kurtosis and skewness of the data (Cullen and Frey, 1999). A Weibull distribution was fitted to the logarithm of suction stress with a maximum likelihood algorithm, and the shape $(\lambda)$ and scale factors $(\kappa)$ of the distribution were found as $6 \cdot 16863$ and $2 \cdot 81378$, respectively. A normal distribution was used for the slope angle with a mean of $32.3^{\circ}$ and a standard deviation of $5 \cdot 24^{\circ}$. Two-sided Kolmogorov-Smirnov tests were applied to these two data sets and the selected distributions in order to test the validity of the choices. $p$ values of 0.3536 and 0.8163 were obtained for the logarithm of suction stress and slope angle, respectively. It can be concluded that the chosen distributions were good approximations as the null hypothesis cannot be rejected. Random data sets were generated with the distribution parameters shown in Figures 3(b) and 3(c) for suction stress and slope angle.

\section{Simulations}

Monte Carlo simulations were performed using the randomly generated data with varying depth. The effects of size of the randomly generated data and the number of simulations were investigated by calculating the FoS using the results of 10 to 1000000 simulations. An increased number of simulations, $N$, did not cause any significant changes in the mean FoS, or the standard deviation, as illustrated in Figure 4(a). However, the cumulative frequency of the simulations yielding a failure $(\mathrm{FoS}<1)$ increased, when the number of simulations was extended from 10 to 1000 (See Figure 4(b)). Percentages of the simulations with a FoS smaller than 1 remained unaffected if the calculations were repeated 10000 or 1000000 times.
An intermediate value of $N=100000$ was chosen as the final number of simulations.

Three sets of Monte Carlo simulations, each with a data size of 100000 , were performed to define the critical suction stress and slope angle values with varying depth. The deterministic values of shear strength parameters of Praettigau soil under saturated conditions, mean unit weight from the experiments and the randomly generated data sets for suction stress and slope angle were used in the simulations. Each simulation was repeated for the depth values of $0.93 \mathrm{~m}, 1.22 \mathrm{~m}$ and $1.48 \mathrm{~m}$. These depths were chosen from the landslide database to be statistically representative for the Praettigau landslides, corresponding to the first quartile, mean and third quartile values of the critical depths, respectively.

\section{Results}

Figures 5(a)-5(c) illustrate the frequency distributions and fitted log-normal distributions with increasing depth values. The summary of the distributions can be found in Figure 5(e). The results of the simulations yielded mean FoS values of $1.33,1.14$ and 1.03 for depths of $0.93 \mathrm{~m}, 1.22 \mathrm{~m}$ and $1.48 \mathrm{~m}$, with standard deviations of $0 \cdot 34,0 \cdot 28$ and $0 \cdot 24$, respectively. The increase in depth resulted in a higher percentage of simulations with an $\mathrm{FoS}<1$, as shown in Figure 5(d). A failure scenario was indicated in $15 \cdot 2 \%, 34 \cdot 7 \%$ and $51 \cdot 4 \%$ of the simulations.

The slope angles and suction stresses of all simulations are shown in Figures 6(a)-6(c). Two clearly distinct point clouds depict the stable and unstable zones of slope angle-suction stress combinations in each figure. Simulations that yielded a FoS less than 1 and higher than 0.995 were used to perform a regression analysis to separate the stable and unstable zones. Second-order polynomials were fitted $\left(R^{2}=0.99, p<0.001\right)$,

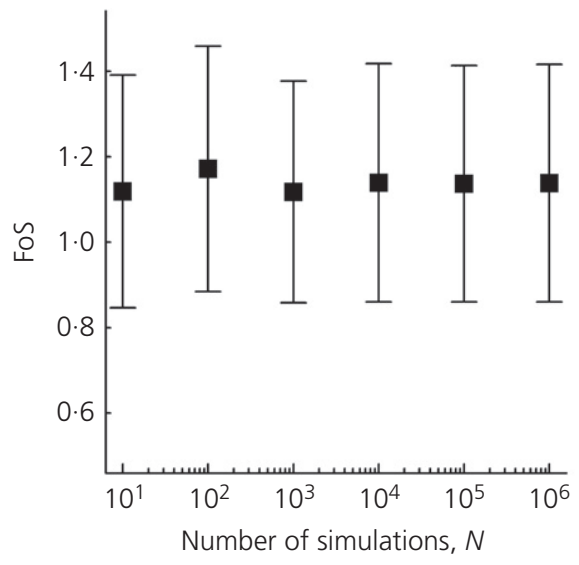

(a)

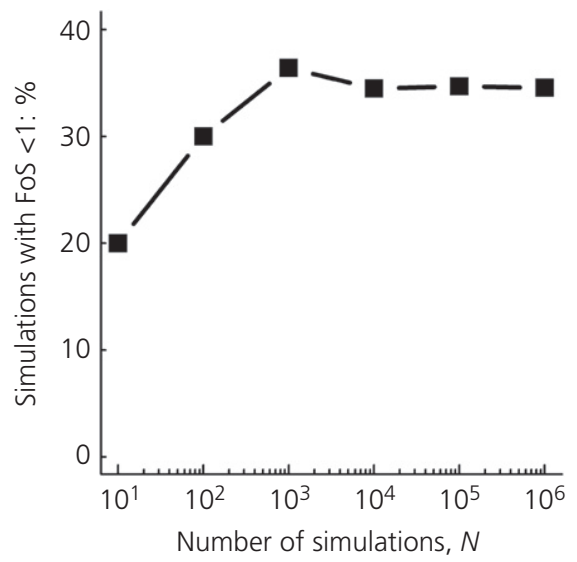

(b)

Figure 4. (a) Change in mean FoS with varying number of simulations $(N)$, error bars show the standard deviation. (b) Percentage of simulations yielding a FoS smaller than 1 according to the number of simulations 


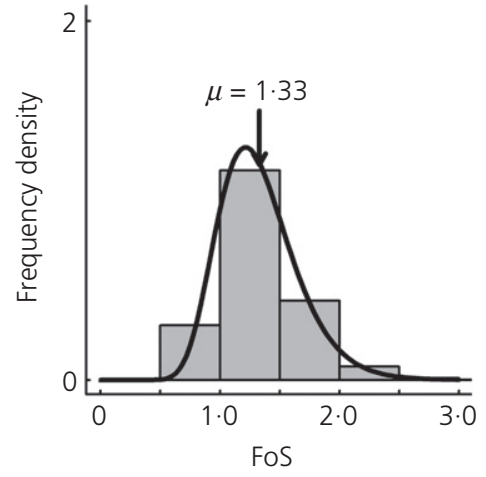

(a)

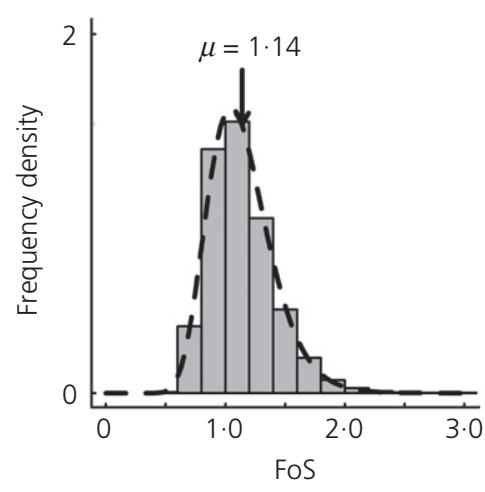

(b)

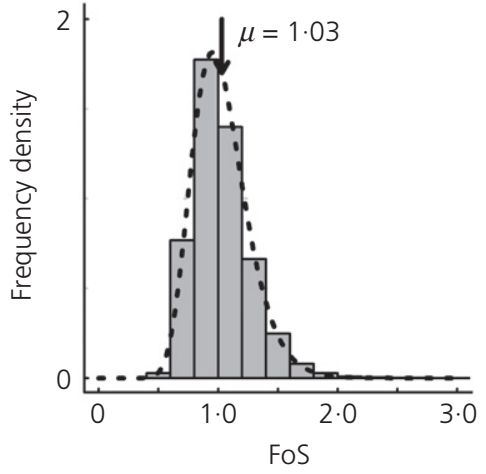

(c)

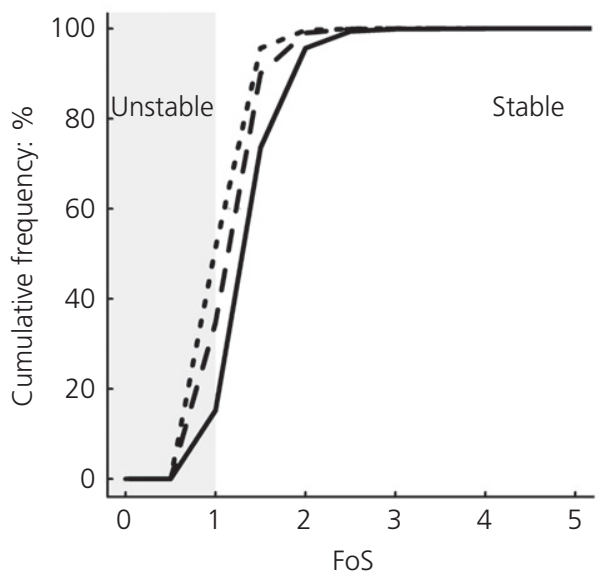

\begin{tabular}{llll}
\hline$z: \mathrm{m}$ & Distribution & $\mu_{\mathrm{InFoS}}$ & $\sigma_{\mathrm{InFoS}}$ \\
\hline 0.93 & Log-normal & 0.25432 & 0.24597 \\
1.22 & Log-normal & 0.10058 & 0.23301 \\
1.48 & Log-normal & 0.00194 & 0.22461 \\
\hline
\end{tabular}

(e)

$-z=0.93 \mathrm{~m} \quad-\quad-z=1.22 \mathrm{~m} \quad \ldots z=1.48 \mathrm{~m}$

(d)

Figure 5. Frequency densities of calculated FoS from Monte Carlo simulations with depths of (a) $0.93 \mathrm{~m}$, (b) $1.22 \mathrm{~m}$ and (c) $1.48 \mathrm{~m}$. (d) Cumulative frequency distributions of the FoS and (e) the fitted distributions

and the fitting parameters are given in the figures as well. Suction stress values between 0 and $60 \mathrm{kPa}$, as used on the axes of Figures 6(a)-6(c), were converted first to matric suction values using Equation 2. Then, these values were converted to gravimetric water content by substituting them into the SWRC for Praettigau soil.

\section{Discussion}

The outcome of this retrospective analysis - that is, the separation between the stable and unstable zones of the slope angle-suction stress graph with varying depth, can be used as a tool to carry out a quick determination of slope stability. It requires the monitoring of volumetric water content or matric suction at different depths, knowledge of the SWRC and determination of the slope angle from geographical information system (GIS) applications or field measurements. This analysis was conducted only for the Praettigau region, and the results in Figures 5 and 6 are particular to these conditions. However, this approach can be transferred to other regions known to be susceptible to shallow landslides, given that a suitable $L / z$ and reasonably consistent soil properties are guaranteed. Furthermore, the shear strength parameters of the soil should be known, and the fitted distributions of the randomly generated data can be validated for this method to be applied to other locations. This model has the advantage of using real statistical distributions for the randomly generated data instead of assuming a uniform distribution (Lee et al., 2013).

The modelling approach presented herein is mainly sustained by results from the direct shear experiments conducted with and inclinable large-scale direct shear apparatus (Yildiz et al., 2019). Normal stresses at the peak shear stress within that investigation were composed of the applied normal load and overburden pressure due to soil weight, and ranged between $7 \cdot 2 \mathrm{kPa}$ and $20 \cdot 7 \mathrm{kPa}$. This range corresponds to a soil thickness of $0 \cdot 36-1 \cdot 04 \mathrm{~m}$ in the field, using the average unit weight from the experiments. Although the applied normal stresses in the experiments do not cover the whole range of depths of shallow landslides in Praettigau, they still overlap with the stresses the soil would experience for the lower values of depth in the database.

Conversion of matric suction measurements into suction stress with the parameters of SWRC is essential for the method 


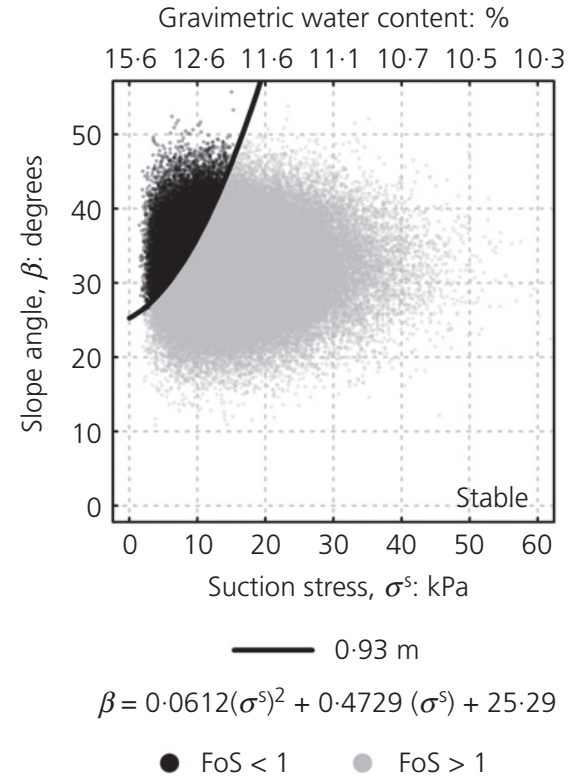

(a)

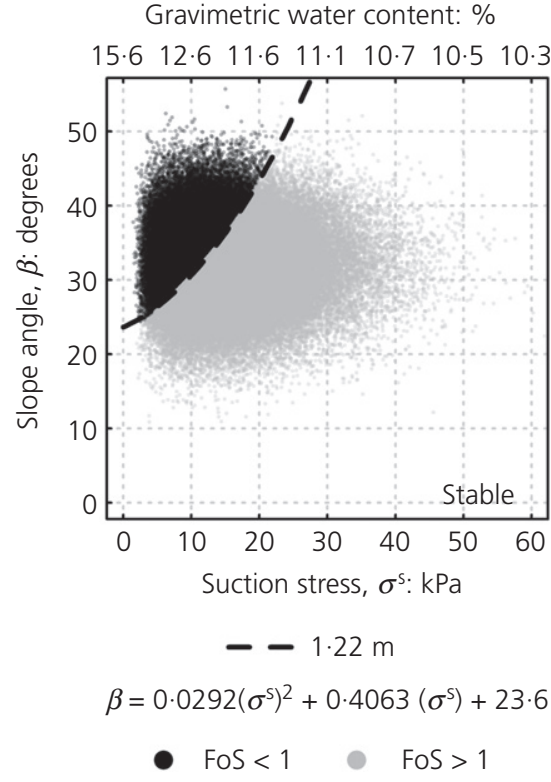

(b)

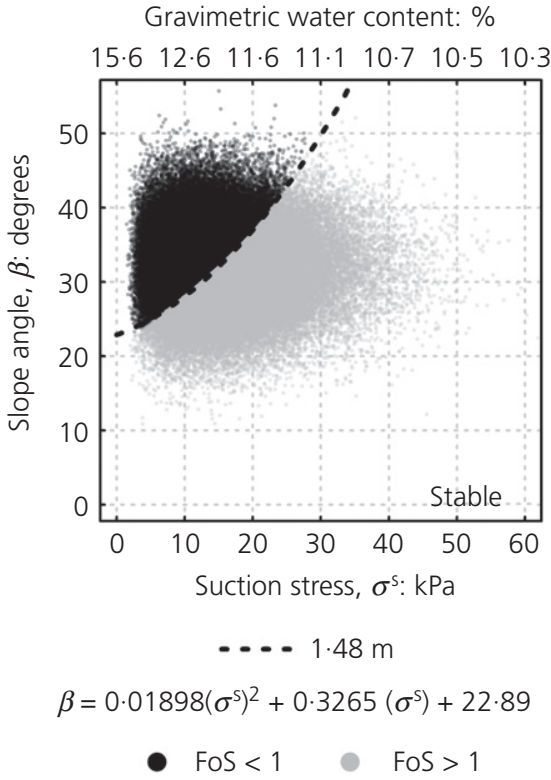

(c)

Figure 6. Slope angle and suction stresses of the Monte Carlo simulations ( $N=100000$ each) that yielded a FoS less than 1 for shear planes at depths below the surface of (a) $0.93 \mathrm{~m}$, (b) $1.22 \mathrm{~m}$ and (c) $1.48 \mathrm{~m}$. Solid and dashed lines show the nominal separation between a stable and an unstable slope, and are given as an equation. Gravimetric water contents are converted from matric suction values using the fitted curve from the equation by Van Genuchten (1980)

proposed. The SWRC is normally determined from laboratory specimens (c. $50 \mathrm{~mm}$ dia. and $20 \mathrm{~mm}$ in depth), which should be sampled to be appropriately undisturbed, should not contain macro drainage features (e.g. channels left by old roots) and should be subjected to relevant boundary conditions. Mayor et al. (2018) investigated the differences in the determination of the SWRC for the same soil from field measurements and laboratory specimens. The ground drained more quickly and much more freely in the field, because drainage was not limited to nominal one-dimensional (1D) conditions. He also fitted both sets of data to the SWRC computed by two methods derived from the soil particle size distribution: the modified Kovács (MK) (Aubertin et al., 2003) and the Arya and Paris (1981) equations (A\&P). The MK method predicted the measured SWRCs well in the zone between the air entry values and the residual zone, whereas the A\&P method performed better in the low-suction zone up to the air entry value.

Consequently, the rather time-consuming and demanding requirements to obtain samples and to carry out laboratory tests for limited benefit, led to a pragmatic approach being adopted in this study to obtain the SWRC of Praettigau soil. The MIT technique, which couples the matric suction measurements from tensiometers with the calculated gravimetric water content values from mass measurements (Toker et al., 2004), was used to determine the SWRC with a simplistic set-up, which provides 1D drainage. Application of this method to other soils and locations requires determination of the SWRC that is representative of the boundary conditions.

The second part of the analysis focuses on the understanding of the initiation of each landslide in the Praettigau region after the rainfall event in 2005. Initially, the same shear strength parameters in the first part of the analysis were used, while the geometry of each slope, depth and slope angle, was taken from the landslide database. When the FoSs from these slopes, which had already failed, were calculated, based on Equation 1 , all the values were less than 1 , indicating that the slopes failed when the matric suction was lost due to saturation after the rainfall. Afterwards, the critical suction stresses to keep the slopes marginally stable $(\mathrm{FoS}=1)$ were calculated, as shown in Figure 7(a) for forested slopes and slopes on open land. The slopes in the forest would require a mean suction stress of $11.7 \mathrm{kPa}$, with a standard deviation of $8.87 \mathrm{kPa}$, whereas those in open land would need a mean value of $11.1 \mathrm{kPa}$, with a standard deviation of $6.66 \mathrm{kPa}$. No significant differences were found in the requirement of suction stress for a FoS of 1, even though the geometric parameters of the landslides between the forest and open land were different (see Figures 7(a) and 7(b)).

Figures 7(a) and 7(b) also suggest that the required suction stresses increase with depth and the slope angle, both for slopes in the forest and in open land. The back-calculated values from the landslide database were compared to the suction stresses from experiments with Praettigau soil. 


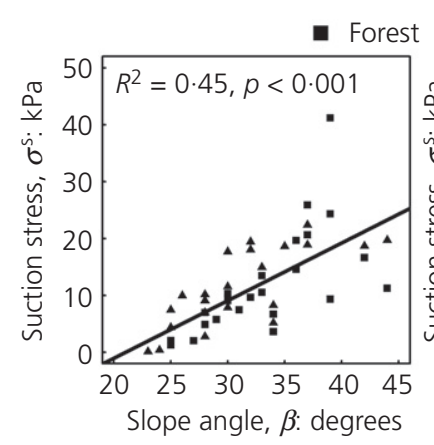

(a)

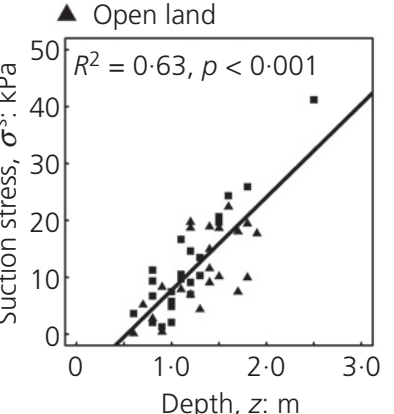

(b)

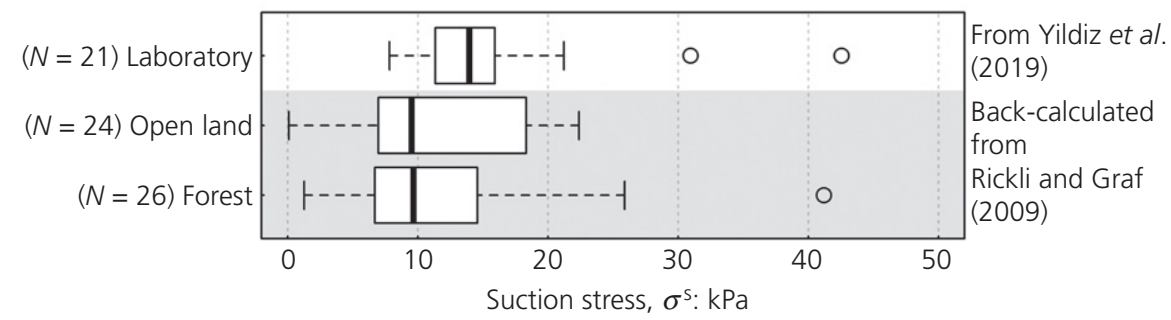

(c)

Figure 7. The required suction stress based on infinite slope analyses to keep the Praettigau slopes stable (FoS $=1$ ) plotted against (a) the slope angle and (b) the depth. (c) Comparison of the required suction stresses calculated from the database and measured in the laboratory

Figure 7(c) shows that the critical suction values were reached with the same soil and different combinations of vegetation in the experiments - that is, the slopes were stable prior to saturation during rainfall, due to the plant-induced suction. Rickli et al. (2019) showed that the study site had a relatively open forest structure - namely, $15-70 \%$ of forest cover, with forest gaps of considerable length, which was shown to be a highly critical parameter in terms of landslide susceptibility (Moos et al., 2016).

The results presented in Yildiz et al. (2019) showed clearly the increase in the shear strength of Praettigau soil with plant-induced suction. Furthermore, matric suction was correlated with root biomass and root:shoot ratio. The plantinduced suction would be expected to be greater with increasing root biomass, either due to plant age or increasing biodiversity.

Measurements of plant-induced suction that consider the influences of biodiversity, inoculation with mycorrhizal fungi and growth duration have provided valuable insight regarding what range of matric suction values can be obtained with different combinations. This insight can be used in combination with the method depicted in Figure 6 as a quick tool to assess the stability of the slopes in the Praettigau region, as the additional contribution to shear strength from the increase in effective stress is lost progressively during infiltration of rainfall, leading to instabilities, sometimes even before full saturation is reached (Springman et al., 2003).

\section{Conclusion}

A physically based landslide susceptibility model based on plant-induced suction measurements under laboratory conditions and information from a landslide database is proposed herein. Monte Carlo simulations performed for an infinite slope stability analysis at different depths yielded combinations of suction stress and slope angle, which can cause slope instability. Retrospective analyses of the landslides showed that monitoring a hydrological parameter of the soil, such as water content or matric suction, together with the knowledge of slope angle and critical state friction angle of the soil, can be used as an early warning tool for landslide susceptibility for the Praettigau study site.

\section{REFERENCES}

Arya LM and Paris JF (1981) A physicoempirical model to predict the soil moisture characteristic from particle-size distribution and bulk density. Soil Science Society of America Journal 45(6): 1023-1030.

Aubertin M, Mbonimpa M, Bussière B and Chapuis RP (2003) A model to predict the water retention curve from basic geotechnical properties. Canadian Geotechnical Journal 40(6): 1104-1122, https://doi.org/10.1139/t03-054.

Bezzola GR and Hegg C (2007) Ereignisanalyse Hochwasser 2005, Teil 1 - Prozessse, Schäden und erste Einordnung. Bundesamt für Umwelt BAFU, Eidgenössiche Forschungsanstalt WSL (in German).

Boldrin D, Leung AK and Bengough AG (2018) Hydrologic reinforcement induced by contrasting woody species during summer and winter. Plant and Soil 427(1-2): 369-390, https://doi.org/10.1007/s11104-018-3640-7. 
Böll A, Burri K, Gerber W and Graf F (2009) Long-term studies of joint technical and biological measures. Forest Snow and Landscape Research 82(1): 9-32.

Brand EW, Premchitt J and Phillipson HB (1984) Relationship between rainfall and landslides in Hong Kong. In Proceedings of the 4th International Symposium on Landslides, Toronto, vol. 1, pp. 377-384

Chirico GB, Borga M, Tarolli P, Rigon R and Preti F (2013) Role of vegetation on slope stability under transient unsaturated conditions. Procedia Environmental Sciences 19: 932-941, https://doi.org/10.1016/j.proenv.2013.06.103.

Cullen A and Frey C (1999) Probabilistic Techniques in Exposure Assessment. Plenum Press, New York, NY, USA.

D'Amato Avanzi G, Giannecchini R and Puccinelli A (2004) The influence of the geological and geomorphological settings on shallow landslides. An example in a temperate climate environment: the June 19, 1996 event in northwestern Tuscany (Italy). Engineering Geology 73(3): 215-228, https://doi.org/10.1016/ j.enggeo.2004.01.005.

Dapples F, Oswald D, Raetzo H, Lardelli T and Zwahlen P (2003) New records of Holocene landslide activity in the western and eastern Swiss Alps: implication of climate and vegetation changes. Eclogae Geologicae Helvetiae 96: 1-9.

Graf F, Frei M and Böll A (2009) Effects of vegetation on the angle of internal friction of a moraine. Forest, Snow and Landscape Research 82(1): 61-77.

Gray DH and Barker D (2004) Root-soil mechanics and interactions. In Riparian Vegetation and Fluvial Geomorphology (Bennett SJ and Simon A (eds)). American Geophysical Union, Washington, DC, USA, pp. 113-123.

Greco R, Guida A, Damiano E and Olivares L (2010) Soil water content and suction monitoring in model slopes for shallow flowslides early warning applications. Physics and Chemistry of the Earth, Parts A/B/C 35(3-5): 127-136, https://doi.org/10.1016/ j.pce.2009.12.003.

Griffiths DV, Huang J and Fenton GA (2011) Probabilistic infinite slope analysis. Computers and Geotechnics 38(4): 577-584, https://doi.org/10.1016/j.compgeo.2011.03.006.

Guzzetti F, Cardinali M, Reichenbach P et al. (2004) Landslides triggered by the 23 November 2000 rainfall event in the Imperia Province, Western Liguria, Italy. Engineering Geology 73(3-4): 229-245, https://doi.org/10.1016/j.enggeo.2004.01.006.

Hazra B, Gadi V, Garg A , Ng CWW and Das GK (2017) Probabilistic analysis of suction in homogeneously vegetated soils. CATENA 149(1): 394 401, https://doi.org/10.1016/ j.catena.2016.10.014

Hilker N, Badoux A and Hegg C (2009) The Swiss flood and landslide damage database 1972-2007. Natural Hazards and Earth System Sciences 9(3): 913-925, https://doi.org/10.5194/nhess-9-913-2009.

Jeangros B and Thomet P (2004) Multi-functionality of grassland systems in Switzerland. In Land Use Systems in Grassland Dominated Regions (Lüscher A, Jeangros B, Huguenin O et al. (eds)). AGFF, Zurich, Switzerland, pp. 11-23.

Kim JH, Fourcaud T, Jourdan C et al. (2017) Vegetation as a driver of temporal variations in slope stability: the impact of hydrological processes. Geophysical Research Letters 44(10): 4897-4907, https://doi.org/10.1002/2017GL073174.

Lee H, Park H, Woo I and Um J (2013) Analysis of landslide susceptibility using Monte Carlo simulation and GIS. In Landslide Science and Practice (Margottini C, Canuti P and Sassa K (eds)). Springer-Verlag, Berlin/Heidelberg, Germany, pp. 371-378

Leung AK and Ng CWW (2013) Analyses of groundwater flow and plant evapotranspiration in a vegetated soil slope. Canadian Geotechnical Journal 50(12): 1204-1218, https://doi.org/10.1139/cgj-2013-0148.
Leung FTY, Yan WM, Hau BCH and Tham LG (2015) Root systems of native shrubs and trees in Hong Kong and their effects on enhancing slope stability. CATENA 125: 102-110, https://doi.org/10.1016/j.catena.2014.10.018.

Leung AK, Kamchoom V and Ng CWW (2017) Influences of root-induced soil suction and root geometry on slope stability: a centrifuge study. Canadian Geotechnical Journal 54(3): 291-303, https://doi.org/10.1139/cgj-2015-0263.

Liang T and Knappett JA (2015) Centrifuge modelling of vegetated slopes under earthquake loading. In Proceedings of the 6th International Conference on Earthquake Loading, Christchurch, New Zealand.

Lu N and Godt J (2008) Infinite slope stability under steady unsaturated seepage conditions. Water Resources Research 44(11): 1-13, https://doi.org/10.1029/2008WR006976.

Lumb PB (1975) Slope failures in Hong Kong. Quarterly Journal of Engineering Geology and Hydrogeology 8(1): 31-65, https://doi.org/10.1144/GSL.QJEG.1975.008.01.02.

Mao Z, Yang M, Bourrier F and Fourcaud T (2014) Evaluation of root reinforcement models using numerical modelling approaches. Plant and Soil 381(1-2): 249-270, https://doi.org/10.1007/ s11104-014-2116-7.

Mayor PA, Springman SM and Morales WF (2018) Water retention curves of a dyke: in situ vs laboratory determination. In Proceedings of the 7th International Conference on Unsaturated Soils (UNSAT2018) (Ng CWW, Leung AK, Chiu ACF and Zhou C (eds)). The Hong Kong University of Science and Technology, Hong Kong, China, pp. 753-758.

Milledge DG, Griffiths DV, Lane SN and Warburton J (2012) Limits on the validity of infinite length assumptions for modelling shallow landslides. Earth Surface Processes and Landforms 37: 1158-1166, https://doi.org/10.1002/esp.3235.

Moos C, Bebi P, Graf F et al. (2016) How does forest structure affect root reinforcement and susceptibility to shallow landslides? Earth Surface Processes and Landforms 41(7): 951-960, https://doi.org/10.1002/esp.3887.

Picarelli L, Comegna L, Gariano SL et al. (2016) Potential climate changes in Italy and consequences for land stability. In Slope Safety Preparedness for Impact of Climate Change (Ho K, Lacasse $\mathrm{S}$ and Picarelli L (eds)). CRC Press, London, UK, pp. 151-198.

Pohl M, Alig D, Körner C and Rixen C (2009) Higher plant diversity enhances soil stability in disturbed alpine ecosystems. Plant and Soil 324(1-2): 91-102, https://doi.org/10.1007/ s11104-009-9906-3.

Pollen-Bankhead N and Simon A (2010) Hydrologic and hydraulic effects of riparian root networks on streambank stability: is mechanical root-reinforcement the whole story? Geomorphology 116(3-4): 353-362, https://doi.org/10.1016/ j.geomorph.2009.11.013.

Rahardjo H, Satyanaga A, Leong EC, Santoso VA and Ng YS (2014) Performance of an instrumented slope covered with shrubs and deep-rooted grass. Soils and Foundations 54(3): 417-425, https://doi.org/10.1016/j.sandf.2014.04.010.

Rickli C and Graf F (2009) Effects of forests on shallow landslides - case studies in Switzerland. Forest Snow Landscape Research 82(1): 33-44.

Rickli C, Bebi P, Graf F and Moos C (2019) Shallow landslides: retrospective analysis of the protective effects of forest and conclusions for prediction. In Recent Advances in Geotechnical Research (Wu W (ed.)). Springer International Publishing AG, Cham, Switzerland, pp. 175-185.

Schwarz M, Giadrossich F and Cohen D (2013) Modeling root reinforcement using a root-failure Weibull survival function. Hydrology and Earth System Sciences 17: 4367-4377, https://doi.org/10.5194/hess-17-4367-2013. 
Geotechnical Engineering

Volume 172 Issue GE6
An investigation of plant-induced suction

and its implications for slope stability

Yildiz, Graf and Springman
Simon A and Collison AJC (2002) Quantifying the mechanical and hydrologic effects of riparian vegetation on streambank stability. Earth Surface Processes and Landforms 27: 527-546, https://doi.org/10.1002/esp.325.

Springman SM, Jommi C and Teysseire P (2003) Instabilities on moraine slopes induced by loss of suction: a case history. Géotechnique 53(1): 3-10, https://doi.org/10.1680/geot.2003.53.1.3.

Stampfli A and Zeiter M (2004) Plant regeneration directs changes in grassland composition after extreme drought: a 13-year study in southern Switzerland. Journal of Ecology 92: 568-576, https://doi.org/10.1111/j.0022-0477.2004.00900.x.

Toker NK, Germaine JT, Sjoblom KJ and Culligan PJ (2004) A new technique for rapid measurement of continuous soil moisture characteristic curves. Géotechnique 54(3): 179-186, https://doi.org/10.1680/geot.2004.54.3.179.

Urciuoli G, Pirone M, Comegna L and Picarelli L (2016) Long-term investigations on the pore pressure regime in saturated and unsaturated sloping soils. Engineering Geology 212: 98-119, https://doi.org/10.1016/j.enggeo.2016.07.018.

Wu W and Sidle RC (1995) A distributed slope stability model for steep forested basins. Water Resources Research 31(8): 2097-2110, https://doi.org/10.1029/95WR01136.

Wu TH, McKinnell WP III and Swanston DN (1979) Strength of tree roots and landslides on Prince of Wales Island, Alaska. Canadian Geotechnical Journal 16(1): 19-33, https://doi.org/ 10.1139/t79-003.

Yildiz A (2017) SOSTANAH - Direct Shear Experiments on Root Permeated Soils Under Partially Saturated Conditions. Mendeley Data, https://doi.org/http://dx.doi.org/10.17632/y7w4jb37gc.1.

Yildiz A, Graf F, Rickli C and Springman SM (2019) Assessment of plant-induced suction and its effects on the shear strength of rooted soils. Proceedings of the Institution of Civil Engineers - Geotechnical Engineering, https://doi.org/10.1680/ jgeen.18.00209.

\section{How can you contribute?}

To discuss this paper, please email up to 500 words to the editor at journals@ice.org.uk. Your contribution will be forwarded to the author(s) for a reply and, if considered appropriate by the editorial board, it will be published as discussion in a future issue of the journal.

Proceedings journals rely entirely on contributions from the civil engineering profession (and allied disciplines). Information about how to submit your paper online is available at www.icevirtuallibrary.com/page/authors, where you will also find detailed author guidelines. 